\title{
Pairing analysis and in situ Hybridisation reveal autopolyploid-like behaviour in Solanum commersonii $\times$ S. tuberosum (potato) interspecific hybrids
}

\author{
Paola Gaiero • Cristina Mazzella $\cdot$ Francisco Vilaró • Pablo Speranza • \\ Hans de Jong (iD
}

Received: 29 December 2016/ Accepted: 29 May 2017/Published online: 14 June 2017

(C) The Author(s) 2017. This article is an open access publication

\begin{abstract}
Wild potato relatives are rich sources of desirable traits for introgressive hybridisation into cultivated potato. One of them, Solanum commersonii ( $2 \mathrm{n}=2 \mathrm{x}=24,1 \mathrm{EBN}$, endosperm balance number), is an important species belonging to the potato tertiary genepool. It can be used in potato breeding through bridge crosses and $2 \mathrm{n}$ gamete production. Triploid $\mathrm{F}_{1}$ hybrids between $S$. commersonii (through spontaneous 2n egg formation) and diploid 2EBN Solanum tuberosum Group Phureja were crossed with S. tuberosum Group Tuberosum, resulting in successive backcross 1, 2 and 3 progenies. The main aim of this study was to determine if there are any barriers to homoeologous pairing and recombination in the allotriploid ( $S$. commersonii $\times$ potato) hybrids and their backcrosses, and so to predict if $S$. commersonii chromosomes can be transmitted to the next generation and introgressed into their recipient potato chromosomes. Microscopic
\end{abstract}

P. Gaiero · C. Mazzella · P. Speranza

Department of Plant Biology, Facultad de Agronomía, Universidad de la República, Garzón 780,

12900 Montevideo, Uruguay

P. Gaiero $\cdot$ H. de Jong $(\bowtie)$

Laboratory of Genetics, Wageningen University,

Droevendaalsesteeg 1, P.O. Box 16,

6708 PB Wageningen, The Netherlands

e-mail: hans.dejong@wur.nl

F. Vilaró

Horticulture Unit, National Institute for Agricultural

Research, Ruta 48 km 10, Las Brujas, Uruguay observations of spread pollen mother cells suggested no preferential pairing in the triploid hybrids, while chromosome transmission and segregation in further meiotic stages were fairly balanced. Fluorescent in situ hybridisation with BAC probes (BAC FISH) was used to obtain markers to trace the meiotic behaviour of specific chromosome pairs. Moreover, genomic in situ hybridisation (GISH) demonstrated no obvious differences in fluorescence signals between the homoeologues suggesting that repetitive sequences did not diverge much between the parental species. As a consequence, we were not able to trace the course of the $S$. commersonii chromosomes in the successive introgressive hybridisation backcross generations. Our results strongly point at a high genomic similarity between the homoeologous chromosomes promising high suitability of $S$. commersonii in introgressive hybridisation breeding of potato.

Keywords Potato wild relatives - Introgressive hybridisation · Pairing behaviour - GISH · BAC FISH
Abbreviations
EBN Endosperm balance number
BAC Bacterial artificial chromosome
FISH Fluorescent in situ hybridisation
GISH Genomic in situ hybridisation
BC Backcross
PMC Pollen mother cells
Cy3 Cyanine 3-dUTP 
Cy3.5 Cyanine 3.5-dCTP

Cy5 Cyanine 5-dUTP

DEAC Diethylaminocoumarin-5-dUTP

DAPI 4',6-diamidino-2-phenylindole

FITC Fluorescein isothiocyanate

\section{Introduction}

Cultivated and wild relatives of potato comprise a huge germplasm resource, more diverse and accessible than that of any other crop (Hawkes 1966; Ross 1986; Hanneman 1989; Peloquin et al. 1989; Hawkes 1990). The collection provides essential genetic traits for many of the biotic and abiotic threats to the crop (Jansky 2000; Solomon-Blackburn and Barker 2001; Jansky and Peloquin 2006; Hamernik et al. 2009), which can be transferred to selected cultivars by introgressive hybridisation. The rich gene pool also contributes to allelic diversity for breeding programmes, and so determines the prospect for selecting desired allele combinations and maximizing heterozygosity, required for yield improvements (Mendoza and Haynes 1974).

However, crossing and zygotic barriers in the interspecific hybrids and backcross derivatives, particularly in those belonging to the secondary and tertiary genepool (Bradshaw 2007), may impede the introgression programmes and thus, considerable efforts have been devoted to overcoming such barriers (reviewed by Jansky 2006) by ploidy manipulation (reviewed by Ortiz 1998; Ortiz et al. 2009) and/or bridge crosses (Jansky and Hamernik 2009). The most prominent hybridisation barrier in the potato gene pool is endosperm balance number (EBN). The EBN hypothesis (Johnston et al. 1980) proposes that each Solanum species has a specific empirical EBN and that for a cross to be successful a 2:1 maternal to paternal EBN ratio is required in the hybrid endosperm. EBN is not directly linked to ploidy level but ploidy manipulation helps overcome the EBN hybridisation barrier (Johnston and Hanneman 1982). Crossability is then routinely evaluated through pollen stainability, an indirect measurement of fertility in the hybrids and backcrosses.

One important representative of the potato tertiary genepool is Solanum commersonii. This species harbours resistances to various biotic stresses such as
Phytophtora infestans (Micheletto et al. 2000), Ralstonia solanacerum (González et al. 2013) and other severe potato pathogens, such as Pectobacterium, Verticillium, Alternaria, and X and Y viruses (Laferriere et al. 1999; Carputo et al. 2000). Additionally, $S$. commersonii has long received attention because of its frost tolerance and cold acclimation capacity (Palta and Li 1979; Palta and Simon 1993; Vega et al. 2000), and it is therefore an outstanding source for broadening the genetic base of cold and drought adaptation (Chen et al. 1999). A few accessions of this species have been used in potato introgression breeding (Bamberg et al. 1994; Carputo et al. 1997, 2000, 2009; Laferriere et al. 1999; Chen et al. 1999). However, interactions at the cytogenetic level have not been described and thus the efficiency of introgression is not completely understood.

A strategy based on the production of unreduced gametes was designed to start a hybridisation programme to introgress resistance to Ralstonia solanacearum and broaden the genetic base of the potatoes cultivated in Uruguay (González 2010). This strategy differs from previous schemes such as the one presented by Carputo et al. (1997) in that it makes use of the natural production of unreduced gametes in $S$. commersonii and in that it takes advantage of the variability generated by meiosis, instead of using ploidy manipulations to overcome the EBN barrier (Fig. 1). A diploid Solanum tuberosum Group Phureja clone was used in the initial cross to overcome incongruity between the species. The $\mathrm{F}_{1}$ plants were used as female parents for backcross $1\left(\mathrm{BC}_{1}\right)$ progenies, again through spontaneous unreduced gametes and with a $S$. tuberosum Group Tuberosum clone as male parent. Successive backcrosses with different $S$. tuberosum Group Tuberosum genotypes produced advanced backcross progenies.

The degree of homoeologous pairing and recombination in interspecific hybrids can be assessed directly by analysing pollen mother cells at diakinesis and later meiotic stages. When combined with genomic in situ hybridization (GISH) to discriminate parental genomes, pairing analysis allows tracing alien chromosomes in the recipient background. This approach has been used in interspecific hybrids of various Solanum species, showing the parental chromosomes in $S$. etuberosum (+) potato (Dong et al. 1999; Gavrilenko et al. 2003), S. nigrum (+) potato (Horsman et al. 2001), S. bulbocastanum (+) potato (Iovene et al. 
Fig. 1 Introgressive hybridisation breeding crossing scheme between $S$. commersonii and $S$. tuberosum Group Tuberosum, using $S$. tuberosum Group Phureja as bridge cross species (González 2010). This crossing scheme produced the $\mathrm{F}_{1}, \mathrm{BC}_{1}$ and $\mathrm{BC}_{2}$ progenies analysed in this study

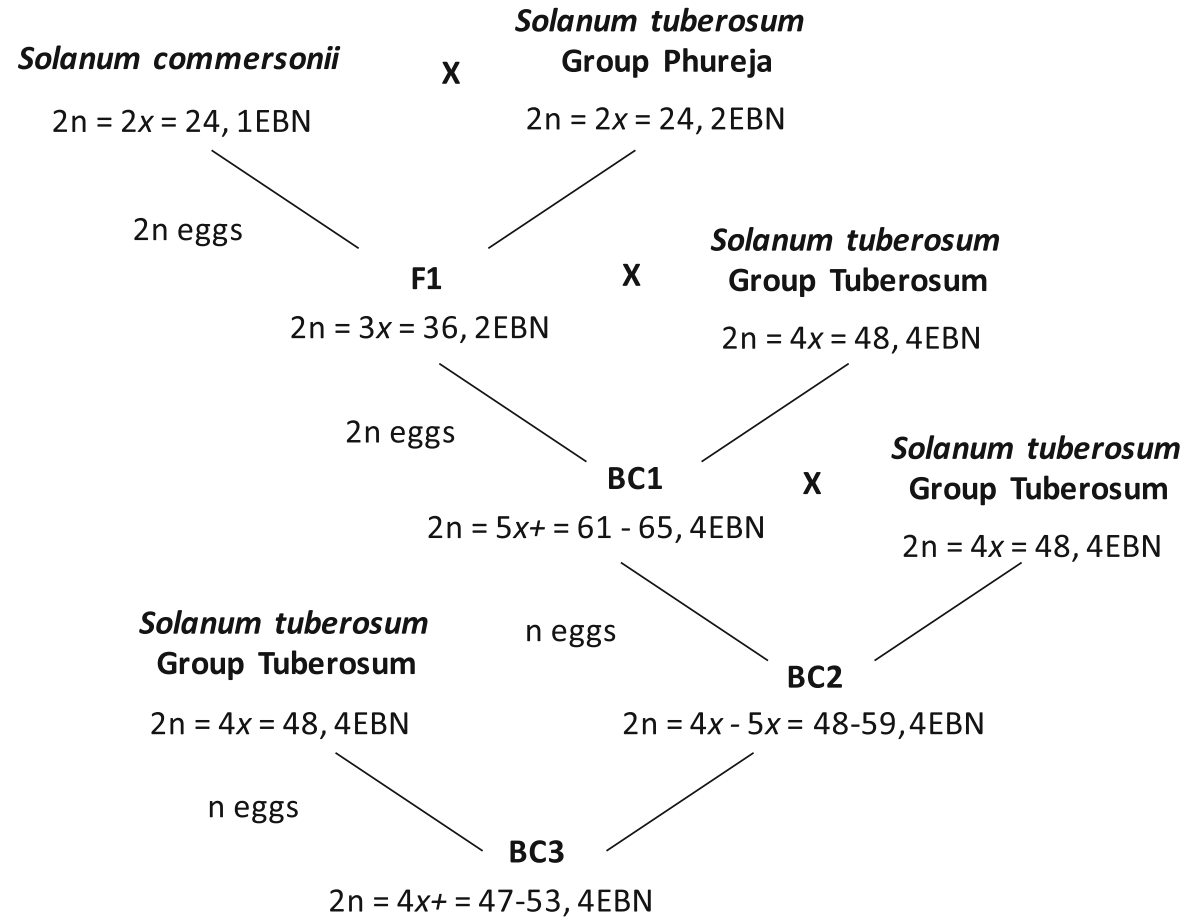

2007) and S. brevidens (+) potato hybrids (Dong et al. 2001; Gavrilenko et al. 2002; Dong et al. 2005) and potato-S. brevidens chromosome substitution lines (Tek et al. 2004). Cross-species BAC-FISH painting can be useful to compare chromosome-specific markers between one species and its relative (Dong et al. 2000). These markers have proved useful to analyse the behaviour of the corresponding chromosomes or chromosome regions during mitosis and meiosis (Schubert et al. 2001; Lysak et al. 2003; McKee 2004). They also constitute a powerful tool for karyotyping in species with small chromosomes or across related species (Dong et al. 2000) and to identify extra chromosomes in aneuploids (Ji 2014) or chromosomes containing genes responsible for resistance traits (Tek et al. 2004). When GISH was combined with chromosome-specific molecular markers the transmission and segregation of individual chromosomes could be traced in potato $(+)$ tomato fusion hybrids (Jacobsen et al. 1995; Garriga-Calderé et al. 1997, 1998, 1999) and wide potato hybrids (Ono et al. 2016). This approach has also been used to elucidate the genomic constitution of wild allopolyploid species (Pendinen et al. 2008, 2012). The limitation of the GISH technology in discriminating parental chromosomes in hybrids is that it depends on how much species-specific tandem and dispersed repeats have diverged in the progenitors and this is still unknown for $S$. commersonii, S. tuberosum Group Phureja and S. tuberosum Group Tuberosum.

According to Matsubayashi (1991), many diploid species in the genome classifications of section Petota share a common genome called A. Their diploid hybrids demonstrate regular meiosis with good pollen fertility. Lack of genome differentiation has been proposed for Solanum section Petota (Camadro et al. 2004), although some cryptic variants were described by Matsubayashi (1991). These variants are not visible in the meiotic behaviour of diploid hybrids and result in a more or less reduced pollen fertility. In amphiploids frequent preferential pairing was observed. Definite structural variants were also described, based on various meiotic irregularities and low pollen fertility (around 10\%) in the diploid hybrids (Matsubayashi 1991). The factors underlying the observed meiotic behaviour and pollen fertility were not clarified with the approaches available at that moment. Although he proposes that $S$. commersonii, $S$. tuberosum Group Phureja and S. tuberosum Group Tuberosum share two A genomes, with two extra $A^{t}$ genomes in tetraploid potato, it is not clear to what extent the differences across these species are cryptic 
or genuine and if such dissimilarities affect homoeologous pairing and recombination. If such variants reflect quantitative or qualitative changes in the repetitive sequences it may be possible to visualise such genomic differentiation through GISH.

In this study, we focused on whether there was evidence of restrictions to pairing and recombination between the chromosomes of $S$. commersonii and $S$. tuberosum (both Group Phureja and Group Tuberosum). We analysed the male meiosis of triploid interspecific hybrids to test if there was preferential pairing between the two $S$. commersonii genomes and exclusion of the $S$. tuberosum Group Phureja chromosomes. We also attempted to follow the fate of specific chromosomes in these triploid hybrids and successive introgressive hybridisation backcrosses, both through BAC FISH markers and genome painting (GISH).

\section{Materials and methods}

Plant material and slide preparation

We described homoeologous pairing in the male meiosis of individuals from the introgressive hybridisation breeding programme described in Fig. 1, namely two allotriploid interspecific hybrids code named 06.201.6 and 06.201.20 $(2 n=3 \mathrm{x}=36$, $2 \mathrm{EBN}$ ) to test the scenario of preferential pairing and clones from the $\mathrm{BC}_{1}$ and $\mathrm{BC}_{2}$ progenies (Table 1) to look at pairing and follow the fate of alien chromosomes in the successive backcrosses.

For chromosome counts, root tips were pre-treated with $2 \mathrm{mM}(\mathrm{w} / \mathrm{v})$ aqueous 8-hydroxyquinoline for $4 \mathrm{~h}$ at $20^{\circ} \mathrm{C}$ and $20 \mathrm{~h}$ at $4^{\circ} \mathrm{C}$, fixed in a 3:1 ethanol-acetic acid solution for $48 \mathrm{~h}$, followed by $70 \%$ ethanol and stored at $4^{\circ} \mathrm{C}$. We performed digestion with an enzyme mix containing 2\% (w/v) pectinase (from Aspergillus niger, Sigma Aldrich, St. Louis, MO, USA, P-4716) and 2\% (w/v) cellulase RS (Yakult 203033, Yakult Pharmaceutical, Tokyo, Japan) in $10 \mathrm{mM}$ Na citrate buffer ( $\mathrm{pH} 4.5)$ for $2-4 \mathrm{~h}$ at $37^{\circ} \mathrm{C}$. Slides were prepared following the squashing method in $45 \%$ acetic acid and stained using with $5 \mu \mathrm{g} / \mathrm{mL}$ DAPI in Vectashield anti-fade (Vector Laboratories). For the analyses of meiotic stages, we harvested young flower buds in the morning (11-12 am) and fixed them directly in 3:1 ethanol: acetic acid as described above. For the study of early meiotic stages, we prepared spread preparations of pollen mother cell (PMC) complements following the procedure described in Szinay et al. (2008) with minor modifications. For meiotic cells at diakinesis and later stages, we used the squashing method. Briefly, anthers previously selected for these stages were digested for $2-4 \mathrm{~h}$ at $37^{\circ} \mathrm{C}$ in an enzyme mix of $1 \%(\mathrm{w} / \mathrm{v})$ pectolyase $\mathrm{Y} 23$ (pectolyase from Aspergillus japonicus, Sigma Aldrich, St. Louis, MO, USA, P-3026), 1\% (w/v) cellulase RS (Yakult 203033, Yakult Pharmaceutical, Tokyo, Japan) and $1 \%(\mathrm{w} / \mathrm{v})$ cytohelicase (cytohelicase from Helix pomatia, Sigma Aldrich, St. Louis, MO, USA, C8274) diluted 1:5 in $10 \mathrm{mM}$ citrate buffer ( $\mathrm{pH} 4.5$ ). Individual anthers were transferred to $30-40 \mu \mathrm{L} 60 \%$ acetic acid and squeezed carefully with fine needles to release the PMC. 8-10 $\mu \mathrm{L}$ of the cell suspension were dropped onto the clean slide and a $24 \times 50 \mathrm{~mm}$ coverslip was put on top. We alternated treatment at $55^{\circ} \mathrm{C}$ for $30-60 \mathrm{~s}$, with $10-20 \mathrm{~s}$ at about $20^{\circ} \mathrm{C}$. This procedure was repeated as many times as necessary for about $10 \mathrm{~min}$, adding $60 \%$ acetic acid to avoid preparation from drying. The preparation was then firmly squashed and the coverslip was removed after freezing in liquid nitrogen. Pollen stainability was measured by shaking mature flowers on slides and staining the pollen with $1 \%$ aceto-carmine.

Probe and blocking DNA isolation and in situ hybridisation

BAC clones used for FISH were obtained from the RHPOTKEY potato BAC library constructed from the RH clone RH89-039-16 and had previously been selected by Tang et al. (2009) for each of the twelve potato linkage groups. BAC DNA was isolated using the QIAGEN (Valencia, CA) plasmid minikit and amplified using the REPLI-g minikit (QIAGEN). Pools of BACs for each chromosome were either directly labelled with Cyanine 3-dUTP (Cy3, Enzo Life Sciences), Cyanine 3.5-dCTP (Cy3.5, GE Healthcare, Sweden) or Diethylaminocoumarin-5-dUTP (DEAC, Perkin Elmer Inc.), or indirectly labelled biotin-16-UTP or digoxigenin-11-dUTP by standard nick translation reaction (Roche Diagnostic, Indianapolis). Probes with the 5S rDNA from the pCT4.2 plasmid (Campell et al. 1992) and 18-35S rDNA from the pTa71 plasmid (Gerlach and Bedbrook 1979) were used as chromosome markers for pairs 1 and 2 respectively, and also as hybridisation controls. 
Table 1 Overview of the plant material used in this study. Pedigree, ploidy, chromosome number, 18-35S and 5S rDNA sites and pollen stainability of the parental, F1 hybrid, backcross 1 (BC1) and $\mathrm{BC} 2$ genotypes analysed

\begin{tabular}{|c|c|c|c|c|c|}
\hline Germplasm type & Genotype & Pedigree & $\begin{array}{l}\text { Ploidy and chromosome } \\
\text { number }\end{array}$ & $\begin{array}{l}\text { 18-35S/5S rDNA } \\
\text { sites }\end{array}$ & $\begin{array}{l}\text { Pollen stainability } \\
(\%)\end{array}$ \\
\hline Wild species & 04.02 .3 & $\mathrm{cmm}$ & $2 n=2 x=24$ & $2 / 2$ & 89 \\
\hline \multirow{4}{*}{$\begin{array}{c}\text { Cultivated } \\
\text { potatoes }\end{array}$} & 94.212 .2 & phu & $2 n=2 x=24$ & $2 / 2$ & 95 \\
\hline & $\begin{array}{l}\text { CIP } \\
38228416\end{array}$ & $78 \mathrm{~A} 1-8 \times \mathrm{G} 5264.1$ & $2 n=4 x=48$ & $4 / 4$ & 82 \\
\hline & 8809.2 & Cupids $\times$ Bulk CIP & $2 n=4 x=48$ & $4 / 4$ & $80-90$ \\
\hline & Atlantic & Wauseon $\times$ Lenape & $2 n=4 x=48$ & $4 / 4$ & 19 \\
\hline \multirow[t]{2}{*}{ F1 hybrids } & 06201.6 & $04.02 .3 \times 94,212.2$ & $2 n=3 x=36$ & $3 / 3$ & 15 \\
\hline & 06201.20 & $04.02 .3 \times 94,212.2$ & $2 \mathrm{n}=3 \mathrm{x}=36$ & $3 / 3$ & 18 \\
\hline \multirow[t]{3}{*}{ Backcross 1} & 08301.1 & $\begin{array}{c}06201.6 \times \mathrm{CIP} \\
38228416\end{array}$ & $2 n=5 x=63$ & $4 / 6$ & 40 \\
\hline & 08302.2 & $\begin{array}{c}06201.20 \times \mathrm{CIP} \\
38228416\end{array}$ & $2 n=5 x=61$ & $5 / 6$ & 36 \\
\hline & 08302.4 & $\begin{array}{l}06201.20 \times \mathrm{CIP} \\
38228416\end{array}$ & $2 n=5 x=65$ & $6 / 6$ & 39 \\
\hline \multirow[t]{7}{*}{ Backcross 2} & 09.505 .1 & $08302.2 \times 8809.2$ & $2 n=4 x-5 x=54$ & $5 / 4$ & $20-30$ \\
\hline & 09.505 .3 & $08302.2 \times 8809.2$ & $2 n=4 x-5 x=53$ & $4 / 5$ & $20-30$ \\
\hline & 09.505 .5 & $08302.2 \times 8809.2$ & $2 n=4 x-5 x=55$ & $4 / 6$ & $20-30$ \\
\hline & 09.509 .1 & $08302.4 \times 8809.2$ & $2 n=4 x-5 x=59$ & $4 / 5$ & $20-30$ \\
\hline & 09509.2 & $08302.4 \times 8809.2$ & $2 n=4 x-5 x=48$ & $5 / 4$ & $20-30$ \\
\hline & 09509.6 & $08302.4 \times 8809.2$ & $2 n=4 x-5 x=56$ & $4 / 6$ & 38 \\
\hline & 09.510 .1 & $08.302 .4 \times \mathrm{BW}$ & $2 n=4 x-5 x=52$ & nd & $20-30$ \\
\hline
\end{tabular}

Genotypes represented in bold were used as parental genotypes for the following F1 or BC progenies

nd not determined

Genomic DNA from the S. commersonii maternal genotype 04.02.3 (Fig. 1) was isolated following the protocol described by Jobes et al. (1995), starting from $5 \mathrm{~g}$ of ground leaf material to obtain larger DNA quantities and concentration and increasing the buffer volumes accordingly. We labelled it with digoxigenin11-dUTP by standard nick translation reaction (Roche Diagnostic, Indianapolis). Additionally, we isolated genomic DNA from $S$. tuberosum cv Desirée also following Jobes et al. (1995) with the minor modifications described and we used it as blocking DNA (100 times probe concentration). FISH and GISH experiments were performed as described previously (Zhong et al. 1996), with the minor modifications introduced by Gaiero et al. (2017). Hybridisation was carried out over 3 days to obtain enhanced signals. Hybridisation of the repetitive sequences in the BAC DNA was suppressed by adding unlabelled $\mathrm{C}_{0 t}-100$ (50 times probe concentration) which was prepared from $S$. commersonii and $S$. tuberosum genomic DNA as described by Tang et al. (2008). In GISH experiments, stringency was adjusted to $80-85 \%$ by performing stringency washes with $50 \%$ formamide/ $2 \times \mathrm{SSC}$ at $42^{\circ} \mathrm{C}$ for $15 \mathrm{~min}$. Chromosomes were counterstained with $5 \mu \mathrm{g} / \mathrm{mL} \quad 4^{\prime}$,6-diamidino-2phenylindole (DAPI) in Vectashield anti-fade (Vector Laboratories).

Image acquisition and processing

We examined the slides under a Zeiss Axioplan 2 imaging photomicroscope (http://www.zeiss.com) with epifluorescence illumination and filter sets for 4',6-diamidino-2-phenylindole (DAPI), DEAC (blue), FITC (green), Cy3 (orange), Cy3.5 (red), and Cy5/ Alexa Fluor 647 (far-red) fluorescence. Selected images were captured using a Photometrics Sensys $1305 \times 1024$ pixel CCD camera (Photometrics, 
http://www.photomet.com). Image thresholding was performed with Adobe ${ }^{\circledR}$ Photoshop ${ }^{\circledR}$ software as follows: DAPI images were displayed in light grey and sharpened using a $7 \times 7$ pixel Hi-Gauss high-pass spatial filter to accentuate minor details and the heterochromatin morphology of the chromosomes. The remaining fluorescence images were pseudo-coloured and overlaid in multichannel mode. Brightness and contrast adjustments were performed using the Levels tool in Adobe $^{\circledR}$ Photoshop $^{\circledR}$ affecting all pixels equally.

\section{Results}

Analysis of homoeologous pairing in 3x hybrids and backcrosses

All $\mathrm{F}_{1}$ hybrids were triploid $(2 n=3 x=36)$, whereas all $\mathrm{BC}_{1}$ have chromosome numbers varying from $2 n=61-65$. Their corresponding $\mathrm{BC}_{2}$ progenies were $4 \mathrm{x}$-aneuploid, ranging from 48 to 59 chromosomes (Table 1).
Detailed meiotic analysis was performed on pollen mother cells (PMC). Frequent trivalents were observed at pachytene, together with bivalents plus single chromosomes (Fig. 2a). Meiotic configurations were studied at diakinesis, when chromosome spreading was sufficient to distinguish the different pairing configurations (Fig. 2b). In the $F_{1}$ allotriploids most chromosomes form trivalents, with an average frequency of 7.3 III, $4.9 \mathrm{II}$ and $4.3 \mathrm{I}$ per cell in a total of 61 cells (Fig. 3). We observed chain, frying-pan and Y-shaped trivalents (Fig. 2b), which are explained by combinations of homologous and homoeologous pairing and crossing over. There were some rare cases of cell complements containing a ring quadrivalent or quinquevalent, probably due to overlapping bivalents and trivalent (data not shown). Later stages demonstrated rare cases of chromosome irregularities (Table 2), including precocious migration and chromosomes out of plate at metaphase I and early anaphase I. We also observed chromosome stickiness (bivalent interconnections) during diakinesis and metaphase I. Anaphase I and II were typical of odd ploidy genotypes with various unbalanced
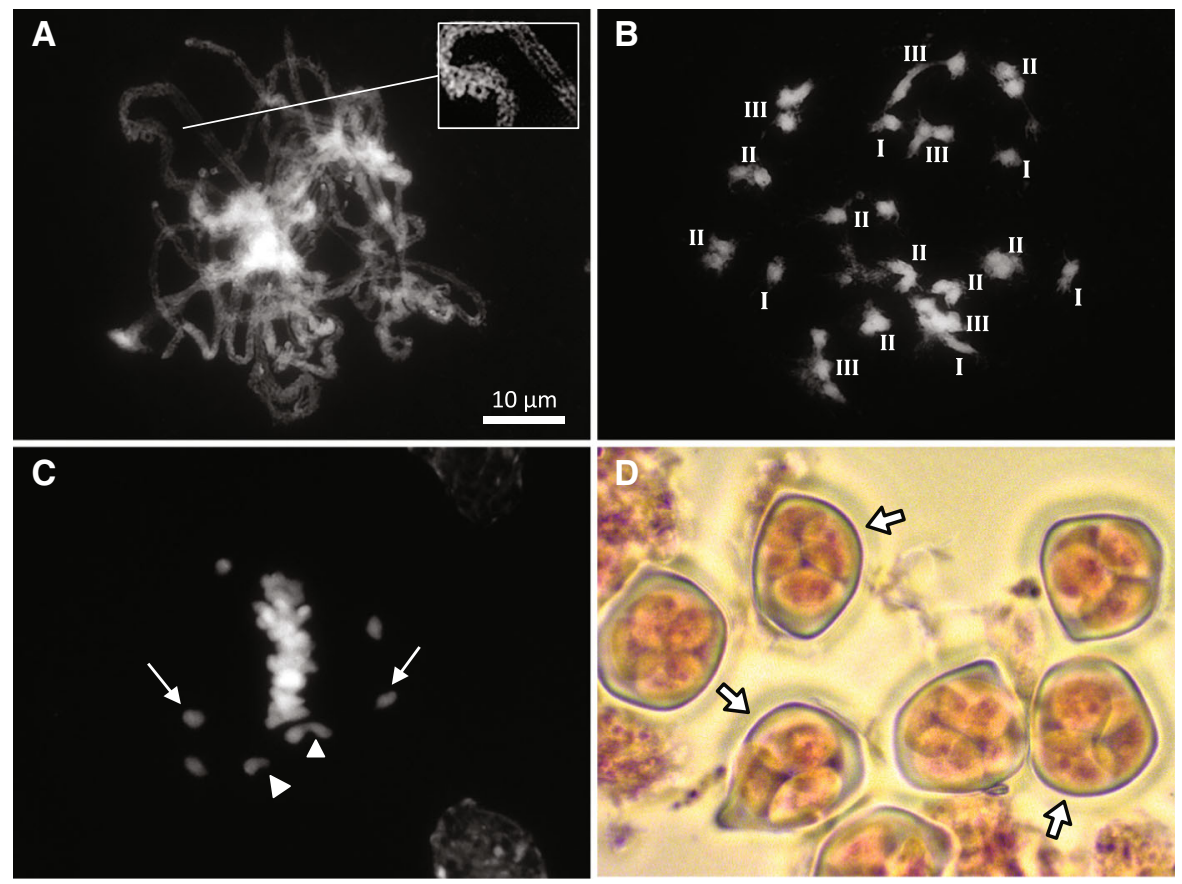

Fig. 2 Homoeologous pairing in pollen mother cells (PMC) from $S$. commersonii and $S$. tuberosum Group Phureja triploids. a Pachytene complement with bivalents and trivalents and a loop (see inset). b Diakinesis showing five trivalents (III), eight bivalents (II) and eight univalents (I). c Metaphase/early

anaphase I complement showing precocious migration (arrows) and univalents and bivalents out of the metaphase plate (arrowhead). d Tetrads and polyads (arrows), aceto-carmine stained cells, bright field microscopy 


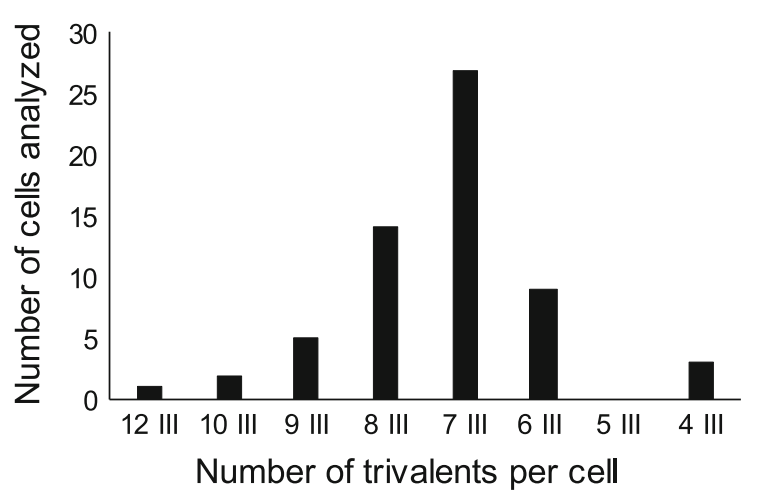

Fig. 3 Distribution of the different numbers of trivalents (III) per cell in the male meiosis of the two $F_{1}$ triploid hybrids analysed together

chromosome distributions (Fig. 2c). We did not detect lagging chromosomes at anaphase I/II and only few cases of anaphase bridges were observed, that apparently resolved at later stages, as telophase I/II PMC did not contain micronuclei (Table 2). Due to an atypical alignment of meiotic spindles, about half of the meiotic products were polyads, while the other half produced tetrads (Fig. 2d; Table 2). This, combined with the typical unbalanced segregation found in odd ploidy genotypes, meant that pollen stainability was on average 17\% (Table 1) so the proportion of fertile pollen was low.

Meiotic analysis was also performed on some $\mathrm{BC}_{1}$ and $\mathrm{BC}_{2}$ individuals. We observed a high proportion of PMCs at pachytene with configuration involving three or more chromosomes, and similar complex multivalents in cells at diakinesis (Fig. 5c, d) and the typical segregation for odd ploidy genotypes in cells at further stages (data not shown). On average, we found 16.2 multivalents, 5.6 II and 2.4 $\mathrm{I}$ in $\mathrm{PMCs}$ at diakinesis from $\mathrm{BC}_{1}$ individuals, while in $\mathrm{BC}_{2}$ we found 12.9 multivalents, $4.3 \mathrm{II}$ and $1 \mathrm{I}$ on average (data not shown). The complexity of homoeologous pairing in these $4 \mathrm{x}$ - and 5x-aneuploids did not allow for detailed descriptions of the composition and configurations of the multivalents. Pollen stainability values are higher in these more advanced backcrosses, with an average of $38 \%$ stainable pollen. This pollen fertility was enough to use one of the $\mathrm{BC}_{2}$ genotypes as male parent for the $\mathrm{BC}_{3}$ progeny.

Identification of meiotic chromosomes

We used chromosome-specific cytogenetic markers to follow the behaviour of the corresponding chromosomes during meiosis. We observed that all chromosomes identified with BAC FISH or rDNA signals were involved in trivalents in most of the complements assessed (Fig. 4a, b). For example, chromosome pair 1 was forming a trivalent in 7 cell complements out of 15 , while chromosome pair 2 was involved in a trivalent in 13 cells and appeared as a univalent plus bivalent in 2 cells (data not shown). We did not find any specific chromosomes that systematically failed to synapse with their homoeologues in the 15 cells quantified i.e., all chromosome pairs were forming trivalents in at least three of the 15 cells assessed (data not shown). Aneuploid individuals in the $\mathrm{BC}_{1}$ and $\mathrm{BC}_{2}$ show variable numbers of rDNA bearing chromosomes (Table 1), suggesting that imbalances may

Table 2 Number and frequency of meiotic irregularities found in the later stages of the male meiosis of Solanum commersonii $\times$ S. tuberosum Group Phureja triploid hybrids

\begin{tabular}{|c|c|c|c|c|c|c|c|}
\hline & Total & Normal & Precocious/out of plate & Bridges & Laggards & Micronuclei & Polyads \\
\hline Metaphase I & 131 & $87(66 \%)$ & $44(34 \%)$ & - & - & - & - \\
\hline Early Anaphase I & 178 & $53(30 \%)$ & $125(70 \%)$ & - & - & - & - \\
\hline Late Anaphase I & 15 & $11(73 \%)$ & - & $4(27 \%)$ & 0 & - & - \\
\hline Telophase I & 17 & $13(77 \%)$ & - & $4(23 \%)$ & 0 & - & - \\
\hline Anaphase II & 38 & $36(95 \%)$ & $2(5 \%)$ & 0 & 0 & - & - \\
\hline Telophase II & 14 & $13(93 \%)$ & - & 0 & 0 & $1(7 \%)$ & - \\
\hline Cytokinesis & 20 & $9(45 \%)$ & - & - & - & - & $11(55 \%)$ \\
\hline Total & 413 & $222(54 \%)$ & $171(41 \%)$ & $8(2 \%)$ & 0 & $1(0.2 \%)$ & $11(2.8 \%)$ \\
\hline
\end{tabular}



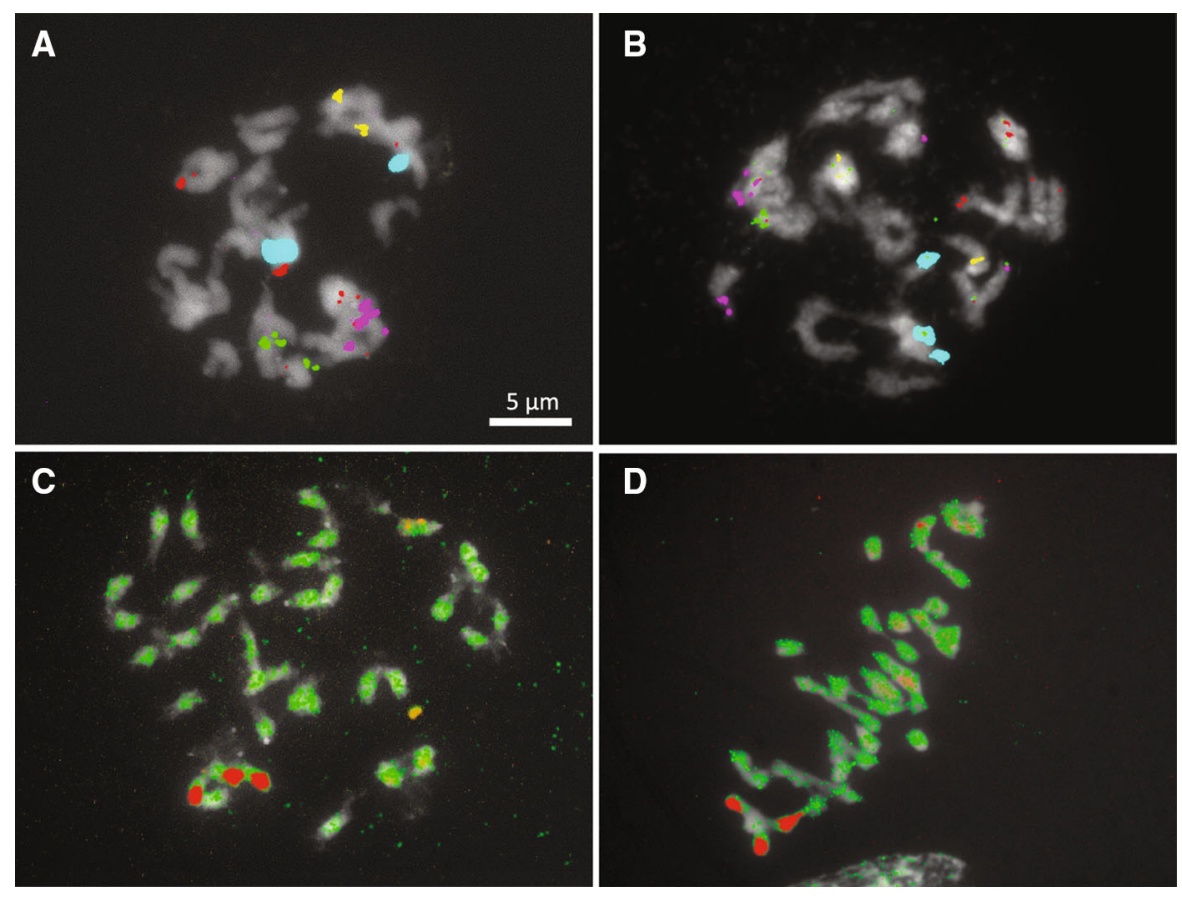

Fig. 4 a Homoeologous pairing in pollen mother cells (PMC) from $3 x$ hybrids between $S$. commersonii and S. tuberosum Group Phureja hybridised with probes specific to chromosome pairs: 1 (yellow), 2 (blue), 3 (purple), 4 (red) and 6 (green) and b 1 (yellow), 2 (blue), 3 (purple), 4 (red) and 7 (green). Chromosomes can be observed forming trivalents or bivalents/

involve different chromosome pairs in each individual.

\section{Genomic in situ hybridisation (GISH)}

To identify $S$. commersonii chromosomes in $\mathrm{F}_{1}$ $3 x$ hybrids and to follow their fate in the successive backcrosses, we performed GISH using S. commersonii genomic DNA as probe and highly stringent blocking with unlabelled cultivated potato genomic DNA. All chromosomes show hybridisation with the $S$. commersonii genomic DNA probe, so it is not possible to discriminate those that come from each parental species (Fig. 4c, d). The hybridisation signal shows the typical dispersed pattern of highly repetitive genome sequences and a stronger signal in the pericentromere region, coherent with the high stringency used in the experiments. These results did not allow us to visualize recombination events or introgressed chromosome segments.

The alien (S. commersonii) chromosomes could not be followed in the successive backcrosses through univalents. c, d Genome painting on pollen mother cells (PMC) from $3 x$ hybrids between $S$. commersonii and $S$. tuberosum Group Phureja using $S$. commersonii genomic DNA as probe (green), 18-35S rDNA (red) and 5S rDNA (yellow) as hybridisation controls in diakinesis and metaphase I, respectively. (Color figure online)

GISH in mitotic metaphases of $\mathrm{BC}_{1}$ and $\mathrm{BC}_{2}$ genotypes (Fig. 5a, b). Although it could be argued that the pericentromere signal is stronger on some of the chromosomes, these quantitative differences cannot be interpreted as qualitative (presence/absence) differences and therefore do not allow us to draw conclusions. Similar results were obtained when we performed GISH painting on diakinesis complements belonging to $\mathrm{BC}_{1}$ and $\mathrm{BC}_{2}$ genotypes (data not shown).

\section{Discussion}

The different approaches used here have allowed us to describe and quantify pairing between the chromosomes of $S$. commersonii and S. tuberosum (both Group Phureja and Group Tuberosum) to find out the extent of homology/homoeology between their genomes. We have not observed any barriers to the exchange of chromosomal segments through the stringent test of homoeologous pairing and 

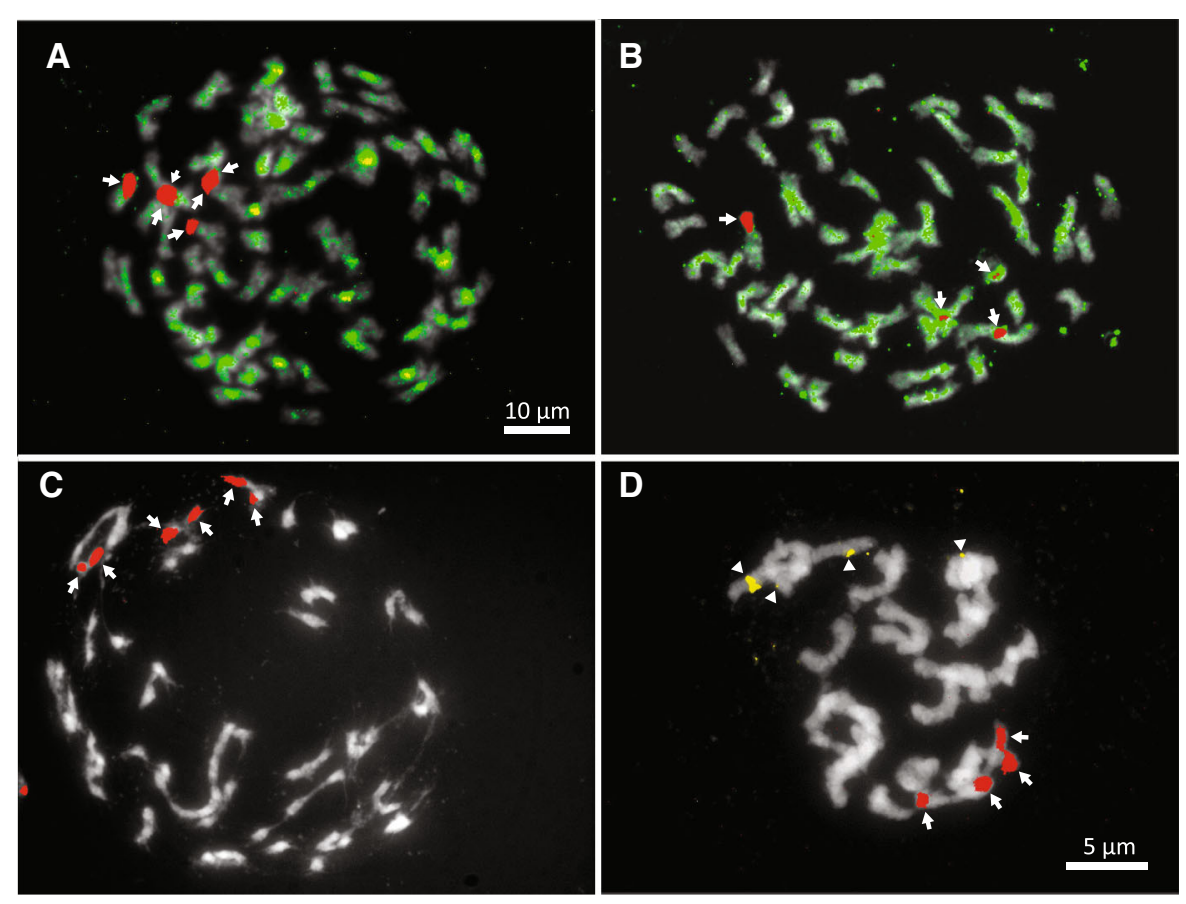

Fig. 5 GISH in the backcrosses. a Genome painting on a mitotic metaphase complement from backcross 1 genotype 08.301.1 $(2 n=5 x+3=63)$ and $\mathbf{b}$ on a mitotic metaphase from backcross 2 genotype $09.509 .6(2 n=4 x-5 x=56)$ using $S$. commersonii genomic DNA as probe (green) and $18-35 \mathrm{~S}$ rDNA (red) as hybridisation control. c Homoeologous pairing in pollen mother cells (PMC) at diplotene/diakinesis from

recombination in triploid hybrids. We have also described the underlying factors that determine crossing success between these species at the cytogenetic level. We observed a high frequency of trivalents per cell, which may allow us to discard preferential pairing between genomes coming from $S$. commersonii and we did not find any evidence of exclusion of S. tuberosum Group Phureja or S. tuberosum Group Tuberosum chromosomes.

We have confirmed that there is frequent homoeologous pairing between the chromosomes of $S$. commersonii and $S$. tuberosum Group Phureja in the triploid hybrids. At pachytene we observed trivalents formed by different chromosome pairs. There was high degree of synapsis and some pairing breaks along the length of the trivalent, which are randomly distributed (Gaiero et al. 2017). In some cases, we observed small loops (inset Fig. 2a), which might represent small local rearrangements. However, a previous study has shown that at the large-scale there backcross 1 genotype $08.302 .4(2 n=5 x+5=65)$ using 18-35S rDNA (red) as probe and $\mathbf{d}$ Homoeologous pairing in PMC at diakinesis from backcross 2 genotype 09.509.2 $(2 n=4 x=48)$ using $18-35 \mathrm{~S}$ rDNA (red) and 5S rDNA (yellow) as probes. In all cases the identified chromosomes are forming multivalents. Arrows indicate 18-35S rDNA sites and arrowheads indicate $5 \mathrm{~S}$ rDNA sites. (Color figure online)

is high collinearity between these two species (Gaiero et al. 2017). Although we have not analysed the female meiosis in these hybrids, its recombination rate is generally higher than in the male meiosis in hermaphroditic plants (reviewed by Lenormand and Dutheil 2005; Wijnker and de Jong 2008). The recombination ratio between male and female meiosis ranged between 0.84 in hybrids between tomato and a wild relative (de Vicente and Tanksley 1991) and 0.73 between potato and a wild relative (Kreike and Stiekema 1997), and was 0.72 in a close wild relative, S. chacoense, (Rivard et al. 1996). Therefore, it can be inferred that the ratio might be similar in the hybrids studied here, and thus that homoeologous pairing could be as frequent or even more frequent in the female meiosis.

At diakinesis, the pairing that was established in earlier stages was maintained and there was high frequency of trivalents (average 7.3 III, 4.9 II and 4.3 I per cell), with a range from 4 III to 12 III per cell 
(Fig. 3). We could observe chiasmata, which confirm previous homoeologous pairing. Although trivalent formation was already reported for $4 \mathrm{x} S$. commersonii $\times 2 \times$ S. tuberosum Group Tuberosum-Group Phureja allotriploids, the authors could not describe or quantify it (Barone et al. 1999). Homoeologous pairing frequencies found here are higher than those found for different allotriploid hybrids between species from different series within section Petota (Lange and Wagenvoort 1973; Masuelli and Camadro 1992). Moreover, our results were the same as those found for autotriploid $S$. tuberosum, with an average of 7.06 III (range 2-12 III) across different autotriploid plants (Lange and Wagenvoort 1973). We frequently found trivalents in Y-shaped or V-shaped configurations, with some frying pan and chain configurations as well. These results suggest recombination among homoeologues in earlier stages. In the case of Y-shaped and frying pan configurations, they point at low interference. These configurations require two crossing-over events in the same arm (Singh 2003). This implies that the introgressed segments are smaller and therefore with lower linkage drag. According to our BAC FISH results, no chromosomes failed to pair systematically (i.e., no chromosomes appeared as a univalent plus a bivalent in all the cells assessed). These results coincide with the high structural collinearity found between $S$. commersonii and $S$. tuberosum by Gaiero et al. (2017). Homoeologous pairing was also observed in $\mathrm{PMC}$ from the $\mathrm{BC}_{1}$ and $\mathrm{BC}_{2}$ progenies, showing mostly multivalents (16 on average in the $\mathrm{BC}_{1}$ and 13 in the $\mathrm{BC}_{2}$ ) with relatively few bivalents and very few univalents. It appears to be higher than that observed by Barone et al. (1999) and Carputo (2003). Put together, our chromosome pairing evidence indicates that the $\mathrm{F}_{1}$ triploid hybrids between S. commersonii and S. tuberosum Group Phureja behave as autotriploids and that homoeologous recombination can take place among all their chromosomes. We have developed a set of $S$. commersoniispecific SSR markers (Sandro et al. 2016) and we are currently testing them in the advanced backcross progenies to follow the fate of $S$. commersonii-specific chromosomal segments and to find conclusive evidence for homoelogous recombination.

Chromosome segregation in further meiotic stages was fairly balanced, with fewer irregularities than those observed in previous studies on triploid hybrids between potato and wild relatives (Adiwilaga and
Brown 1991; Masuelli and Camadro 1992; Carputo et al. 1995). These authors found high frequency of cells with laggards in anaphase I and II. In our case these events were absent, albeit the lower number of cells evaluated (Table 2). The most common irregularities found here were precocious migration/bivalents out of plate, which is a common characteristic of anaphases in Solanum (Ramanna and Hermsen 1982; de Jong et al. 1993; Larrosa et al. 2012). These few irregularities were resolved further on. At telophase I and II most PMC did not contain micronuclei (Fig. 2; Table 2), while they were present in the $4 \mathrm{x} S$. commersonii $\times 2 \times$ S. tuberosum Group TuberosumGroup Phureja analysed by Carputo et al. (1995) and were very common in the $S$. commersonii $\times S$. gourlayi allotriploids (Masuelli and Camadro 1992). According to our results, meiotic products were approximately $50 \%$ polyads and $50 \%$ tetrads (Fig. 2d; Table 2) which could carry unbalanced chromosome numbers. These results are discouraging compared to those obtained by Carputo et al. (1995) and combined with unbalanced segregation, meant that pollen stainability was on average low (17\%). In the past, the only indication of crossability was pollen stainability. In such case, a highly suitable wild donor as $S$. commersonii, would have been discarded without looking at chromosome pairing. However, when pairing takes place, only a few successful crosses are enough to introduce the wild germplasm into the cultivated potato background. In our context this difficulty was overcome because these triploids were successfully used as female parents for the $\mathrm{BC}_{1}$ progenies, through $2 \mathrm{n}$ gametes. These $\mathrm{BC}_{1}$ and $\mathrm{BC}_{2}$ progenies produce higher percentages of stainable pollen (Table 1), as expected from their more balanced genomic contributions.

Great variation in chromosome numbers was found in the $\mathrm{BC}_{1}(2 n=5 \mathrm{x}+=61-65)$ and $\mathrm{BC}_{2}(2 n=4 \mathrm{x}-$ $5 \mathrm{x}=48-59$ ) progenies (Table 1 ). In our case $\mathrm{BC}_{1}$ plants were aneuploid, while Barone et al. (1999) found that most were exact allopentaploids. The cases of 5x-aneuploids were explained in terms of occasional omission of chromosomes in the restitution nuclei forming $2 \mathrm{n}$ eggs (Carputo 2003). The most important post-zygotic barrier in potatoes is EBN. It is not clear yet what factors determine EBN or where they are mapped in the potato genome. Aneuploid gametes with extra chromosomes bearing the EBN controlling factors might be positively selected for 
compatible crosses and thus favour the formation of genotypes with complements higher than the expected $2 n=5 x=60$ (Carputo 1999; Henry et al. 2009). For the $\mathrm{BC}_{2}$ plants Carputo et al. (2003) observed a narrower range of chromosome number variation, with a tendency towards tetraploid $(2 n=4 \mathrm{x}=48)$ numbers. In hybridisation programmes with $S$. tuberosum Group Tuberosum involving other species such as $S$. demissum, in pentaploid $\mathrm{BC}_{1}$ progenies variations in chromosome number were directly related to the amount of wild germplasm in the $\mathrm{BC}_{1}$ plant because the genome from $S$. tuberosum was equally inherited to the progeny (Ono et al. 2016). However, the ranges found here point at random segregation of both homologous and homoeologous chromosomes in the backcross progenies.

Genomic in situ hybridization (GISH) demonstrated hardly any differences in fluorescence signals between the homoeologues, so we were not able to discriminate chromosomes belonging to each species. GISH has been useful to discriminate potato chromosomes from those belonging to species from other Solanum sections like tomato (Jacobsen et al. 1995; Garriga-Calderé et al. 1997, 1998, 1999) or S. nigrum (Horsman et al. 2001). Within section Petota, GISH has been successfully used for hybrids between $S$. tuberosum Group Tuberosum and non-tuber bearing potato relatives carrying the E genome (Matsubayashi 1991), like S. brevidens (Dong et al. 2001; Gavrilenko et al. 2002; Tek et al. 2004; Dong et al. 2005) or $S$. etuberosum (Dong et al. 1999; Gavrilenko et al. 2003). No successful GISH results have been reported for hybrids between potato and its closer A-genome tuberbearing wild relatives, with the exception of $S$. bulbocastanum, a diploid (1EBN, $\mathrm{A}^{\mathrm{b}}$ genome) Mexican species (Iovene et al. 2007). This suggests that repetitive sequences have not diverged much among their genomes, in spite of the estimated 2.3 million years divergence between the species (Aversano et al. 2015).

The low degree of genomic divergence among potato wild relatives contrasts with the results reported for the species of another well studied clade within the same genus: tomato wild relatives. Variable homoeologous recombination rates have been found through molecular markers and sequence data in introgression lines of S. lycopersicoides (Canady et al. 2006) or $S$. pimpinellifolium (Demirci et al. 2017) with tomato. Significant structural rearrangements have been described among species belonging to the tomato clade (Anderson et al. 2010; Verlaan et al. 2011; Szinay et al. 2012). GISH has been successfully applied to tomato hybrids with $S$. peruvianum or $S$. lycopersicoides (Parokonny et al. 1997; Ji and Chetelat 2003; Ji et al. 2004). Results of GISH experiments like those reported here show that the repetitive sequence fraction of the genome has low divergence among potato wild relatives. This compositional difference of the repetitive fractions in the genomes in the potato and tomato clades may itself (through repetitive DNA dynamics) underlie the mechanisms leading to different rates of molecular, pairing and structural chromosome differentiation among potato, tomato and their respective wild relatives. Analyses on the nature, abundance and dynamics of the repetitive fractions of their genomes are currently underway.

The results found in this study are evidence to reinforce the hypothesis of lack of genome differentiation within the potato clade, most likely maintained by (or being a by-product of) pre and post zygotic hybridisation barriers (Carputo et al. 1999; Camadro et al. 2004). Genome similarity between $S$. commersonii and potato must be $85 \%$ or higher, because of the stringency used in GISH experiments and the high blocking conditions. To what extent this is related to homoeologous pairing and recombination is still unclear. A lot remains unknown about the mechanisms that guide homologous pairing (Bozza and Pawlowski 2008), let alone interactions among homoeologues. Although some authors give homology only indirect responsibility for initial pairing (Sybenga 1999), meiotic chromosome pairing is generally accepted to be based on DNA homology. However, it also depends on spatial location (Bozza and Pawlowski 2008). Initial recognition is related to simultaneous conformational changes in chromatin in both partners that can only be triggered by interactions between true homologues, so that they can only pair if they are in the same conformational state (Prieto et al. 2004). It also needs overcoming of compact heterochromatin regions that might be difficult to access and of the spurious pairing that might be caused by repetitive sequences (Bozza and Pawlowski 2008). Similar heterochromatin distribution and condensation together with similar chromosome structures were found between the genomes of $S$. commersonii and $S$. tuberosum Group Phureja (Gaiero et al. 2017). Therefore, the genome similarity found here between 
S. commersonii and S. tuberosum Group Tuberosum must be both at the local and global chromosomal homology levels to ensure the observed pairing.

Our results have important implications for the use of $S$. commersonii in potato introgressive hybridisation breeding. Allotriploids like the ones analysed here are the most stringent test for homoeologous pairing and recombination between two species. Our data show that homoeologous pairing is highly frequent and recombination can take place, as would rather be expected in autotriploids, making introgression of the desired traits possible. It was not possible to discriminate the chromosomes belonging to the parental species or to pinpoint the introgressed chromosomal segments in complements from advanced backcrosses, which would have been valuable tools to assist negative selection for alien chromatin and to confirm introgression. On the other hand, the high genome similarity observed, together with the high collinearity between the two genomes, suggest that introgression of $S$. commersonii chromosomal regions should be highly efficient and the potential of this species for potato breeding can be fully exploited.

Acknowledgements Research was supported by: Agencia Nacional de Investigación e Innovación (ANII) (Grant Code FMV_1_2011_ 1_6697) and Comisión Sectorial de Investigación Científica, University of the Republic, Uruguay (Grant Code CSIC I+D 2012 383). P. Gaiero was supported by Grant Proyecto 720 and CSIC Recursos Humanos, University of the Republic. We are thankful to Elsa Camadro for her very useful suggestions for the project and to José van de Belt and Mariana Andino for their assistance during the development of the experiments. We are grateful to Alicia Castillo and the technical staff at INIA for kindly providing plant material.

Open Access This article is distributed under the terms of the Creative Commons Attribution 4.0 International License (http:// creativecommons.org/licenses/by/4.0/), which permits unrestricted use, distribution, and reproduction in any medium, provided you give appropriate credit to the original author(s) and the source, provide a link to the Creative Commons license, and indicate if changes were made.

\section{References}

Adiwilaga KD, Brown CR (1991) Use of 2n pollen-producing triploid hybrids to introduce tetraploid Mexican wild species germ plasm to cultivated tetraploid potato gene pool. Theor Appl Genet 81(5):645-652. doi:10.1007/ BF00226732
Anderson LK, Covey PA, Larsen LR, Bedinger P, Stack SM (2010) Structural differences in chromosomes distinguish species in the tomato clade. Cytogenet Genome Res 129:24-34. doi:10.1159/000313850

Aversano R, Contaldi F, Ercolano MR et al (2015) The Solanum commersonii genome sequence provides insights into adaptation to stress conditions and genome evolution of wild potato relatives. Plant Cell 27:954-968. doi:10.1105/ tpc.114.135954

Bamberg JB, Hanneman RE, Palta JP, Harbage JF (1994) Using disomic $4 \mathrm{x}(2 \mathrm{EBN})$ potato species' germplasm via bridge species Solanum commersonii. Genome 37:866-870

Barone A, Sebastiano A, Carputo D (1999) Chromosome pairing in Solanum commersonii-S. tuberosum sexual hybrids detected by commersonii-specific RAPDs and cytological analysis. Genome 42:218-224. doi:10.1139/gen-42-2-218

Bozza CG, Pawlowski WP (2008) The cytogenetics of homologous chromosome pairing in meiosis in plants. Cytogenet Genome Res 120:313-319. doi:10.1159/000121080

Bradshaw J (2007) Potato breeding strategy. In: Vreugdenhil D, Bradshaw J, Gebhardt C, Govers F, Mackerron DKL, Taylor MA, Ross HA (eds) Potato biology and biotechnology: advances and perspectives, 1st edn. Elsevier Science, Amsterdam, pp 157-177

Camadro E, Carputo D, Peloquin S (2004) Substitutes for genome differentiation in tuber-bearing Solanum: interspecific pollen-pistil incompatibility, nuclear-cytoplasmic male sterility, and endosperm. Theor Appl Genet 109:1369-1376. doi:10.1007/s00122-004-1753-2

Campell BR, Song Y, Posch TE, Cullis CA, Town CD (1992) Sequence and organization of $5 \mathrm{~S}$ ribosomal RNA-encoding genes of Arabidopsis thaliana. Gene 112:225-228. doi:10. 1016/0378-1119(92)90380-8

Canady MA, Ji Y, Chetelat RT (2006) Homeologous recombination in Solanum lycopersicoides introgression lines of cultivated tomato. Genetics 174:1775-1788. doi:10.1534/ genetics.106.065144

Carputo D (1999) Post-zygotic gametic selection due to endosperm balance number explains unusual chromosome numbers of $3 \mathrm{x} \times 2 \mathrm{x}$ progeny in Solanum. Sex Plant Reprod 12:27-31. doi:10.1007/s004970050168

Carputo D (2003) Cytological and breeding behavior of pentaploids derived from $3 \mathrm{x} \times 4 \mathrm{x}$ crosses in potato. Theor Appl Genet 106:883-888. doi:10.1007/s00122-002-1165-0

Carputo D, Cardi T, Frusciante L, Peloquin SJ (1995) Male fertility and cytology of triploid hybrids between tetraploid Solanum commersonii $(2 \mathrm{n}=4 \mathrm{x}=48,2 \mathrm{EBN})$ and Phureja-Tuberosum haploid hybrids. Euphytica 83(124):123-129. doi:10.1007/BF01678039

Carputo D, Barone A, Cardi T, Sebastiano A, Frusciante L, Peloquin SJ (1997) Endosperm balance number manipulation for direct in vivo germplasm introgression to potato from a sexually isolated relative (Solanum commersonii Dun.). Proc Natl Acad Sci USA 94(22):12013-12017

Carputo D, Monti L, Werner JE, Frusciante L (1999) Uses and usefulness of endosperm balance number. Theor Appl Genet 98:478-484. doi:10.1007/s001220051095

Carputo D, Basile B, Cardi T, Frusciante L (2000) Erwinia resistance in backcross progenies of Solanum tuberosum $\times$ S. tarijense and S. tuberosum (+) S. commersonii hybrids. Potato Res 43:135-142. doi:10.1007/BF02357954 
Carputo D, Parisi M, Consiglio F, Iovene M, Caruso G, Monti L, Frusciante L (2003) Aneuploid hybrids from 5x-4x crosses in potato: chromosome number, fertility, morphology and yield. Am J Potato Res 80:93-101. doi:10.1007/ BF02870208

Carputo D, Aversano R, Barone A, Matteo A, Iorizzo M, Sigillo L, Zoina A, Frusciante L (2009) Resistance to Ralstonia solanacearum of sexual hybrids between Solanum commersonii and S. tuberosum. Am J Potato Res 86:196-202. doi:10.1007/s12230-009-9072-4

Chen Y-KH, Palta JP, Bamberg JB (1999) Freezing tolerance and tuber production in selfed and backcross progenies derived from somatic hybrids between Solanum tuberosum L. and S. commersonii Dun. TAG Theor Appl Genet 99:100-107. doi:10.1007/s001220051213

de Jong J, Wolters A, Kok J, Verhaar H, Eden J (1993) Chromosome pairing and potential for intergeneric recombination in some hypotetraploid somatic hybrids of Lycopersicon esculentum (+) Solanum tuberosum. Genome. doi:10.1139/g93-138

de Vicente MC, Tanksley SD (1991) Genome-wide reduction in recombination of backcross progeny derived from male versus female gametes in an interspecific cross of tomato. Theor Appl Genet 83:173-178. doi:10.1007/BF00226248

Demirci S, van Dijk ADJ, Sanchez Perez G, Aflitos SA, Ridder D, Peters SA (2017) Distribution, position, and genomic characteristics of crossovers in tomato recombinant inbred lines derived from an interspecific cross between $S$. lycopersicum and $S$. pimpinellifolium. Plant $\mathrm{J}$. 89(3):554-564. doi:10.1111/TPJ.13406

Dong F, Novy RG, Helgeson JP, Jiang J (1999) Cytological characterization of potato-Solanum etuberosum somatic hybrids and their backcross progenies by genomic in situ hybridization. Genome 42:987-992. doi:10.1139/gen-425-987

Dong F, Song J, Naess SK, Helgeson JP, Gebhardt C, Jiang J (2000) Development and applications of a set of chromosome-specific cytogenetic DNA markers in potato. Theor Appl Genet 101:1001-1007. doi:10.1007/s001220051573

Dong F, McGrath JM, Helgeson JP, Jiang J (2001) The genetic identity of alien chromosomes in potato breeding lines revealed by sequential GISH and FISH analyses using chromosome-specific cytogenetic DNA markers. Genome 44:729-734. doi:10.1139/gen-44-4-729

Dong F, Tek AL, Frasca ABL, McGrath JM, Wielgus SM, Helgeson JP, Jiang J (2005) Development and characterization of potato-Solanum brevidens chromosomal addition/substitution lines. Cytogenet Genome Res 109:368-372. doi:10.1159/000082421

Gaiero P, van de Belt J, Vilaró F, Schranz ME, Speranza P, de Jong H (2017) Collinearity between potato (Solanum tuberosum L.) and wild relatives assessed by comparative cytogenetic mapping. Genome 60(3):228-240. doi:10. 1139/gen-2016-0150

Garriga-Calderé F, Huigen D, Filotico F, Jacobsen E, Ramanna M (1997) Identification of alien chromosomes through GISH and RFLP analysis and the potential for establishing potato lines with monosomic additions of tomato chromosomes. Genome 40:666-673

Garriga-Calderé F, Huigen D, Angrisano A, Jacobsen E, Ramanna M (1998) BC1 to BC2 progenies derived from backcrossing potato $(+)$ tomato fusion hybrids to potato: the selection of single additions for seven different tomato chromosomes. Theor Appl Genet 96:155-163. doi:10. 1007/s001220050722

Garriga-Calderé F, Huigen DJ, Jacobsen E, Ramanna MS (1999) Prospects for introgressing tomato chromosomes into the potato genome: an assessment through GISH analysis. Genome 42:282-288. doi:10.1139/gen-42-2282

Gavrilenko T, Larkka J, Pehu E, Rokka V-M (2002) Identification of mitotic chromosomes of tuberous and nontuberous Solanum species (Solanum tuberosum and Solanum brevidens) by GISH in their interspecific hybrids. Genome 45:442-449. doi:10.1139/g01-136

Gavrilenko T, Thieme R, Heimbach U, Thieme T (2003) somatic hybrids of Solanum etuberosum (+) dihaploid Solanum tuberosum and their backcrossing progenies: relationships of genome dosage with tuber development. Euphytica 131:323-332. doi:10.1023/A:1024041104170

Gerlach WL, Bedbrook JR (1979) Cloning and characterization of ribosomal RNA genes from wheat and barley. Nucleic Acids Res 7:1869-1885. doi:10.1093/nar/7.7.1869

González M (2010) Análisis de la resistencia a Ralstonia solanacearum en una progenie segregante de Solanum commersonii. MSc Dissertation, Universidad de la República, Uruguay

González M, Galván G, Siri MI, Borges A, Vilaró F (2013) Resistencia a la marchitez bacteriana de la papa en Solanum commersonii. Agrociencia Uruguay 7:45-54. www. scielo.edu.uy/pdf/agro/v17n1/v17n1a05.pdf

Hamernik AJ, Hanneman RE, Jansky SH (2009) Introgression of wild species germplasm with extreme resistance to cold sweetening into the cultivated potato. Crop Sci 49:529. doi:10.2135/cropsci2008.04.0209

Hanneman RE (1989) The potato germplasm resource. Am Potato J 66:655-667

Hawkes JG (1966) Modern taxonomic work on the Solanum species of Mexico and adjacent countries. Am Potato J 43:81-103. doi:10.1007/BF02861580

Hawkes J (1990) The potato: evolution, biodiversity and genetic resources. Belhaven, London

Henry IM, Dilkes BP, Tyagi AP, Lin H-Y, Comai L (2009) Dosage and parent-of-origin effects shaping aneuploid swarms in A. thaliana. Heredity 103:458-468. doi:10. 1038/hdy.2009.81

Horsman K, Gavrilenko T, Bergervoet M, Huigen D, Joe A, Jacobsen E (2001) Alteration of the genomic composition of Solanum nigrum (+) potato backcross derivatives by somatic hybridization: selection of fusion hybrids by DNA measurements. Plant Breed 120:201-207. doi:10.1046/j. 1439-0523.2001.00591.x

Iovene M, Savarese S, Cardi T, Frusciante L, Scotti N, Simon PW, Carputo D (2007) Nuclear and cytoplasmic genome composition of Solanum bulbocastanum (+) S. tuberosum somatic hybrids. Genome 50(5):443-450. doi:10.1139/ G07-024

Jacobsen E, de Jong H, Kamstra S (1995) Genomic in situ hybridization (GISH) and RFLP analysis for the identification of alien chromosomes in the backcross progeny of potato (+) tomato fusion hybrids. Heredity 74:250-257. http:// www.nature.com/hdy/journal/v74/n3/abs/hdy199538a.html 
Jansky SH (2000) Breeding for disease resistance in potato. In: Janick J (ed) Plant breeding reviews 19. Wiley, Oxford, pp 69-152

Jansky SH (2006) Overcoming hybridization barriers in potato. Plant Breed 125:1-12. doi:10.1111/j.1439-0523.2006. 01178.x

Jansky SH, Hamernik A (2009) The introgression of $2 \times 1$ EBN Solanum species into the cultivated potato using Solanum verrucosum as a bridge. Genet Resour Crop Evol 56:1107-1115. doi:10.1007/s10722-009-9433-3

Jansky SH, Peloquin SJ (2006) Advantages of wild diploid Solanum species over cultivated diploid relatives in potato breeding programs. Genet Resour Crop Evol 53:669-674. doi:10.1007/s10722-004-2949-7

Ji X (2014) Numerical and structural chromosome aberrations in cauliflower (Brassica oleracea var. botrytis) and Arabidopsis thaliana. PhD Dissertation, Wageningen University, The Netherlands

Ji Y, Chetelat RT (2003) Homoeologous pairing and recombination in Solanum lycopersicoides monosomic addition and substitution lines of tomato. Theor Appl Genet 106:979-989. doi:10.1007/s00122-002-1090-2

Ji Y, Pertuzé R, Chetelat RT (2004) Genome differentiation by GISH in interspecific and intergeneric hybrids of tomato and related nightshades. Chromosome Res 12:107-116. doi:10.1023/B:CHRO.0000013162.33200.61

Jobes D, Hurley D, Thien L (1995) Plant DNA isolation: a method to efficiently remove polyphenolics, polysaccharides, and RNA. Taxon 44:379-386. doi:10.2307/1223408

Johnston SA, Hanneman RE (1982) Manipulations of endosperm balance number overcome crossing barriers between diploid Solanum species. Science 217:446-448. doi:10. 1126/science.217.4558.446

Johnston S, Den Nijs T, Peloquin S, Hanneman R (1980) The significance of genic balance to endosperm development in interspecific crosses. Theor Appl Genet 57:5-9. doi:10. 1007/BF00276002

Kreike CM, Stiekema WJ (1997) Reduced recombination and distorted segregation in a Solanum tuberosum $(2 \mathrm{x}) \times S$. spegazzinii (2x) hybrid. Genome 40:180-187. doi:10.1139/ g97-026

Laferriere LT, Helgeson JP, Allen C (1999) Fertile Solanum tuberosum $+S$. commersonii somatic hybrids as sources of resistance to bacterial wilt caused by Ralstonia solanacearum. Theor Appl Genet 98:1272-1278. doi:10.1007/ s001220051193

Lange W, Wagenvoort M (1973) Meiosis in triploid Solanum tuberosum L. Euphytica 22:8-18. doi:10.1007/ BF00021550

Larrosa F, Maune J, Erazzú L, Camadro E (2012) Meiotic abnormalities underlying pollen sterility in wild potato hybrids and spontaneous populations. Plant Biol 14:223-233. doi:10.1111/j.1438-8677.2011.00470.x

Lenormand T, Dutheil J (2005) Recombination difference between sexes: a role for haploid selection. PLoS Biol 3:0396-0403. doi:10.1371/journal.pbio.0030063

Lysak MA, Pecinka A, Schubert I (2003) Recent progress in chromosome painting of Arabidopsis and related species. Chromosome Res 11:195-204. doi:10.1023/A:102287 9608152
Masuelli RW, Camadro EL (1992) Cytological analysis and fertility of Solanum commersonii Dun. $\times$ Solunum gourlayi Haw. Triploid hybrids. Cytologia 57:161-166. doi:10. 1508/cytologia.57.161

Matsubayashi M (1991) Phylogenetic relationships in the potato and its related species. In: Tsuchiya T, Gupta P (eds) Chromosome engineering in plants: genetics, breeding, evolution, part B. Elsevier, Amsterdam, pp 93-118

McKee BD (2004) Homologous pairing and chromosome dynamics in meiosis and mitosis. Biochim Biophys Acta 1677:165-180. doi:10.1016/j.bbaexp.2003.11.017

Mendoza HA Haynes FL (1974) Genetic relationship among potato cultivars grown in the United States. Hortscience 9:328-330. http://agris.fao.org/agris-search/search.do?rec ordID=US201303178585

Micheletto S, Boland R, Huarte M (2000) Argentinian wild diploid Solanum species as sources of quantitative late blight resistance. Theor Appl Genet 101(5-6):902-906. doi:10.1007/s001220051560

Ono S, Sanetomo R, Hosaka K (2016) Genetic transmission of Solanum demissum $(2 \mathrm{n}=6 \mathrm{x}=72)$ chromosomes from a pentaploid hybrid of $S$. tuberosum $(2 \mathrm{n}=4 \mathrm{x}=48)$ into the aneuploid BC1 progeny. Euphytica 207:149-168. doi:10. 1007/s10681-015-1558-1

Ortiz R (1998) Potato breeding via ploidy manipulations. In: Janick J (ed) Plant breeding reviews, vol 16. Wiley, Oxford, pp 15-86. doi:10.1002/9780470650110.ch2

Ortiz R, Simon P, Jansky S, Stelly D (2009) Ploidy manipulation of the gametophyte, endosperm and sporophyte in nature and for crop improvement: a tribute to Professor Stanley J. Peloquin (1921-2008). Ann Bot 104:795-807. doi:10. 1093/aob/mcp207

Palta JP, Li PH (1979) Frost hardiness related to leaf anatomy and Solanum spp. distribution. Crop Sci 19:665-671

Palta JP, Simon G (1993) Breeding potential for improvement of freezing stress resistance: genetic separation of freezing tolerance, freezing avoidance, and capacity to cold acclimate. In: Li PH (ed) Advances in plant cold hardiness. CRC Press, Boca Raton, pp 299-310

Parokonny AS, Marshall JA, Bennett MD, Cocking EC, Davey MR, Power JB (1997) Homoeologous pairing and recombination in backcross derivatives of tomato somatic hybrids [Lycopersicon esculentum $(+)$ L. peruvianum]. Theor Appl Genet 94(6-7):713-723. doi:10.1007/ s001220050470

Peloquin S, Jansky S, Yerk G (1989) Potato cytogenetics and germplasm utilization. Am Potato J 66:629-638. doi:10. 1007/BF02853983

Pendinen G, Gavrilenko T, Jiang J, Spooner DM (2008) Allopolyploid speciation of the Mexican tetraploid potato species Solanum stoloniferum and S. hjertingii revealed by genomic in situ hybridization. Genome 51:714-720. doi:10.1139/G08-052

Pendinen G, Spooner DM, Jiang J, Gavrilenko T (2012) Genomic in situ hybridization reveals both auto- and allopolyploid origins of different North and Central American hexaploid potato (Solanum sect. Petota) species. Genome 55:407-415. doi:10.1139/g2012-027

Prieto P, Shaw P, Moore G (2004) Homologue recognition during meiosis is associated with a change in chromatin 
conformation. Nat Cell Biol 6:906-908. doi:10.1038/ ncb1168

Ramanna MS, Hermsen JGT (1982) Gene transfer from nontuberous to tuberous Solanum species: evidence from meiosis in hybrids. Euphytica 31:565-572. doi:10.1007/ BF00039194

Rivard SR, Cappadocia M, Landry BS (1996) A comparison of RFLP maps based on anther culture derived, selfed, and hybrid progenies of Solanum chacoense. Genome 39:611-621. doi: 10.1139/g96-078

Ross H (1986) Potato breeding - problems and perspectives. In: Parey P (ed) Advances in plant breeding. Verlag, Berlin, pp 65-94

Sandro PA, Rebollo MI, Gaiero P, Vaio M, Vilaró F, Speranza P (2016) Diseño de microsatélites para Solanum commersonii a partir de información genómica. ALAG 2016. J Basic Appl Genet. XXVII (1):276. http://www.alag2016. org/admin/files/alag2016/upload/files/V.XXVIII_2016_ Suppl1_19092016.pdf

Schubert I, Fransz PF, Fuchs J, de Jong JH (2001) Chromosome painting in plants. Methods Cell Sci 23(1-3):57-69

Singh RJ (2003) Plant cytogenetics. CRC Press, Boca Raton

Solomon-Blackburn RM, Barker H (2001) Breeding virus resistant potatoes (Solanum tuberosum): a review of traditional and molecular approaches. Heredity 86(1):17-35. https://www.ncbi.nlm.nih.gov/pubmed/11298812

Sybenga J (1999) What makes homologous chromosomes find each other in meiosis? A review and a hypothesis. Chromosoma 108(4):209-219. doi:10.1007/s004120050371

Szinay D, Chang S-B, Khrustaleva L, Peters SA, Schijlen E, Bai Y, Stiekema WJ, van Ham RCHJ, de Jong H (2008) Highresolution chromosome mapping of BACs using multicolour FISH and pooled-BAC FISH as a backbone for sequencing tomato chromosome 6. Plant J 56:627-637. doi:10.1111/j.1365-313X.2008.03626.X

Szinay DD, Wijnker E, van den Berg R, Visser RGF, de Jong H, Bai Y (2012) Chromosome evolution in Solanum traced by cross-species BAC-FISH. New Phytol 195:688-698. doi:10.1111/j.1469-8137.2012.04195.x

Tang X, Szinay D, Lang C, Ramanna MS, van der Vossen EAG, Datema E, Lankhorst RK, de Boer J, Peters SA, Bachem C, Stiekema W, Visser RGF, de Jong H, Bai Y (2008) Crossspecies bacterial artificial chromosome-fluorescence in situ hybridization painting of the tomato and potato chromosome 6 reveals undescribed chromosomal rearrangements. Genetics 180:1319-1328. doi:10.1534/genetics.108. 093211

Tang X, De Boer JM, Van Eck HJ, Bachem C, Visser RGF, De Jong H (2009) Assignment of genetic linkage maps to diploid Solanum tuberosum pachytene chromosomes by BAC-FISH technology. Chromosome Res 17:899-915. doi:10.1007/s10577-009-9077-3

Tek AL, Stevenson WR, Helgeson JP, Jiang J (2004) Transfer of tuber soft rot and early blight resistances from Solanum brevidens into cultivated potato. Theor Appl Genet 109:249-254. doi:10.1007/s00122-004-1638-4

Vega SE, Palta JP, Bamberg JB (2000) Variability in the rate of cold acclimation and deacclimation among tuber-bearing Solanum (potato) species. J Am Soc Hort Sci 125(2): 205-211. http://journal.ashspublications.org/content/125/ $2 / 205$

Verlaan MG, Szinay D, Hutton SF, de Jong H, Kormelink R, Visser RGF, Scott JW, Bai Y (2011) Chromosomal rearrangements between tomato and Solanum chilense hamper mapping and breeding of the TYLCV resistance gene Ty-1. Plant J 68:1093-1103. doi:10.1111/j.1365-313X.2011. 04762.x

Wijnker E, de Jong H (2008) Managing meiotic recombination in plant breeding. Trends Plant Sci 13:640-646. doi:10. 1016/j.tplants.2008.09.004

Zhong XB, de Jong H, Zabel P (1996) Preparation of tomato meiotic pachytene and mitotic metaphase chromosomes suitable for fluorescence in situ hybridization (FISH). Chromosome Res 4:24-28. doi:10.1007/BF02254940 